\title{
Editorial: On IRIE Vol. 23
}

The current European refugee crisis presents a major challenge both politically and economically for the EU and indeed the world. Looking beyond mere operative endeavours, the complexity of the crisis reminds us of the fragility of the assumed structures and organization of our (social) being in the world: questioning our being-as-citizen not only of a homeland but of a nation state as well, where geopolitical, cultural and ethnic standards are challenged. Of course, migration has, in part, defined much of human history, whether at an individual level or in terms of major waves of migration during times of war or ethnic persecution. The present migration crisis is not a novel phenomenon, where the exchange of inherited citizenship and acquired rights for asylum in a foreign land is a familiar tale told many times throughout centuries of geo-political upheaval.

The major difference between human migrations of history and our current crisis is the scale on which it takes place and the complexity of the causation behind it. The readiness to abandon one's homeland for asylum has grown exponentially in recent decades, a willingness hampered traditionally by geological barriers such as the Mediterranean Sea, but barriers of which have now through human desperation for asylum, ceased to be. Where there are no such barriers there are hastily erected fences and walls, a futile attempt to dissuade the tide of desperation, but being just another barrier that cannot withstand the mass movements of displaced peoples frantic in their loss of citizenship and homeland.

How different is the citizenship of the online world: there are virtually no barriers to moving around such a world - not only in terms of global communication but across the entire cosmos of the internet and cyberspace. How easy it becomes to quit an online community in order to move to another, a task accomplished by merely a few clicks. Masses do so, entire communities migrate, moving from 'myspace' to 'facebook', the consequence of which is that once seemingly strong and established communities are abandoned and eventually (sometimes suddenly) cease to exist. Furthermore, the argument is made that we have the 'right to be forgotten' in such a world, that in the internet one should be able to move on without leaving one's mark - forcing our abandoned communities to delete our information and thereby making our digital past unavailable to search engines, and thus to history.

On the other hand: the rules of engagement for online communities are not yet developed to a satisfactory level. Many social networks, for example, claim the right to expel members without having to give sufficient reason to do so and with no proper means to appeal their case. When viewed from the perspective of citizenship, bearing in mind that people already spend more time in their online communities than in offline ones, and that being part of particular communities in the web is becoming more and more important to people as being a citizen of a nation state becomes less and less important, we thoroughly have to understand if and how citizenship - and all the fundamental philosophical reflections associated with it - applies to the infosphere. Such concerns define information ethics at its core and are expounded on as the subject of the following issue.

Yours,

the editors. 